\title{
Potential barriers to the new child's right to appeal to Special Educational Needs and Disability tribunals in Northern Ireland
}

\author{
ORLA DRUMMOND*
}

School of Law, Ulster University

\begin{abstract}
The Special Educational Needs and Disability Act (Northern Ireland) 2016 has changed the legal landscape for those seeking to utilise the Special Educational Needs Tribunal in the event of a dispute regarding special educational provision. The new Act provides children over compulsory school age with the right to request a statutory assessment and the right to appeal to the tribunal against certain decisions of the Education Authority. While these new participative rights are reflective of international obligations emanating from the UNCRC and the UNCRPD, recent research has highlighted a number of procedural and attitudinal barriers which may dilute the effectiveness of the legislation in guaranteeing a child's right to participate at the tribunal. This paper uses new empirical data from key stakeholders in the process to discuss these potential barriers and asserts that implanting a child's right to appeal into a process with preexisting participative barriers will do little to ensure meaningful child participation at SEN tribunals.
\end{abstract}

Special Educational Needs and Disability (SEN) tribunals are independent panels which typically arbitrate in disputes between parents of children with special educational needs and education providers. ${ }^{1}$ Disputes generally concern the level of special educational provision or type of support the child is receiving at school, although claims of disability discrimination are also heard by the tribunal. These types of administrative tribunals permit citizens to individually and directly challenge decisions of the state that they perceive to be inequitable. Their independence and detachment from the original educational decision-maker injects fairness and objectivity into the decision-making process, generating legitimacy, trust and confidence in the wider democratic governance of the state. ${ }^{2}$ Children's right to participate in such judicial and administrative proceedings affecting them is internationally enshrined in Article 12(2) of the UN Convention on the Rights of the Child (UNCRC). ${ }^{3}$ This right may be claimed directly by the child, or through a representative or an appropriate body, in a manner consistent with the procedural rules

* Email: Drummond-o1@email.ulster.ac.uk. This research was funded by the Department of Employment and Learning (NI) PhD Studentship Scheme, the Modern Law Review Scholarship 2013/14 and 2014/15 and the Socio-Legal Studies Association Fieldwork Grant.

1 Previously known as Education and Library Boards.

2 Neville Harris, 'Dispute Resolution in Education: Role Models' in Neville Harris and Sheila Riddell, Resolving Disputes about Educational Provision: A Comparative Perspective on Special Educational Needs (Ashgate 2011) 29; Vicki Lens, 'Administrative Justice in Public Welfare Bureaucracies: When Citizens (Don't) Complain' (2007) 39 Administration and Society 382-408, 382.

3 UNCRC (adopted 20 November 1989, entered into force 2 September 1990) Article 12(2). 
of national law. Article 12(2) is tied to the more general participative rights guaranteed in Article 12(1) which assures children the right to express their views freely in all matters that affect them, the views of the child being given due weight in accordance with the age and maturity of the child.

Theoretically, the SEN tribunal is a prime example of a forum which should guarantee the rights enshrined in Article 12(2), particularly in light of much newer participative rights generated for children with disabilities by Article 7 of the UN Convention on the Rights of Persons with Disabilities (UNCRPD) ${ }^{4}$ and yet research has highlighted that children are rarely party to proceedings and have little influence on the outcome of tribunal decision-making. ${ }^{5}$

In an attempt to redress the gap in child participation at tribunals in Northern Ireland, the new Special Educational Needs and Disability Act $^{6}$ (SEND Act) provides for a new child right of appeal for children of compulsory school age, provided the child is considered to have the capacity to take an appeal forward. This replaces the traditional parental right to appeal and places emphasis on mediation prior to invoking the tribunal. While the rhetoric emanating from the Department of Education of Northern Ireland is welcomingly rights-based, emphasising the necessity to place the child at the centre of the decision-making process and ensuring the provision of necessary information and support to enable participation, the procedural requirements of taking a case to a SEN tribunal and the tribunal environment seem relatively unchanged or impacted upon by the passing of the Act.

This paper will examine new empirical data, gathered from interviews and written submissions from key stakeholders in the tribunal process, in order to conduct a comparative examination of SEN tribunals in Northern Ireland and Wales. The data documents a number of persistent barriers to accessibility and participation at SEN tribunals for current users of this mechanism of legal redress. In essence the paper will suggest that grafting a child's right to appeal on to a process with pre-existing participative barriers may do little to ensure meaningful child participation at SEN tribunals (a process that had little success when piloted in Wales between 2012-2015) and will highlight areas of reform that would be required in order to ensure that participative rights take effect.

\section{Methodology}

The data referred to in this article came from a study which examined, from a child rights perspective, the extent to which SEN tribunals are accessible, enabling and participatory for users, concentrating on barriers to accessibility and participation, and exploring issues which might continue to dissuade users from seeking redress through the tribunal system. The research was comparative in nature, examining differing approaches to tribunal participation in both Northern Ireland and Wales. The decision to examine these two distinct regions comparatively stems from their differing approaches to child participation in the SEN tribunal process.

In Wales, the Education (Wales) Measure 2009 gave children the opportunity to make an appeal or claim themselves, supplementing the traditional parental right to take a case to the Special Educational Needs Tribunal Wales (SENTW). The Welsh government stated that the Measure specifically built on the UNCRC, expanding children's entitlement

4 UNCRPD (adopted 13 December 2006, entered into force 3 May 2008) Article 7.

5 Neville Harris, Sheila Riddell and Emily Smith, 'Special Educational Needs (England) and Additional Support Needs (Scotland) Dispute Resolution Project: Working Paper 1: Literature Review' (University of Manchester 2008) 46.

6 Special Educational Needs and Disability Act (NI) 2016. 
by providing them with a parity of rights their parents already possessed to make SEN appeals and claims of disability discrimination to the tribunal. ${ }^{7}$ In addition the Measure required local authorities to inform children of their appeal rights; placed a new duty on local authorities to make arrangements for, and inform children about, access rights to both partnership and disagreement resolution services; and placed a new duty on local authorities to provide access to independent advocacy services that would listen to and give voice to children's views and concerns. At the time of the study, Northern Ireland retained the traditional parental right to appeal only.

The empirical data was gathered through interviews and written submissions provided by key users, judicial staff, administrative staff and government departments in both Wales and Northern Ireland. These stakeholders included 10 parents from Northern Ireland and nine parents from Wales who had experience of taking a case to tribunal; a child from Northern Ireland who attended tribunal hearings; members of tribunals from both Wales and Northern Ireland; representatives from education authorities; administrative tribunal staff in Wales; interviews with the Department of Education and Skills (Wales); and written submissions from the Northern Ireland Courts and Tribunal Service, the Department of Justice NI and the Department of Education NI.

For the purposes of the research, the term 'child' applies to all persons under the age of 18 as stated in Article 1 of the UNCRC and article 2 of the Children (NI) Order 1995. ${ }^{8}$

\section{New participative rights guaranteed by the SEND Act}

Following the development of and consultation on 'Every School a Good School: The Way Forward for Special Educational Needs and Inclusion' the Department of Education NI secured the enactment of the SEND Act 2016, giving legislative effect to the revised policy on special educational needs and inclusion framework. ${ }^{9}$ The department asserts that the intention of this new policy direction and legislative structure is to ensure early identification, assessment and provision for SEN children in order that they can achieve their full potential, with the child placed firmly at the centre of that process, bringing into domestic legislation a number of aspects of the UNCRC and the UNCRPD. ${ }^{10}$

In Northern Ireland the definition of 'special educational needs' (SEN) is laid out in article 3(1) of the Education (NI) Order 1996 (the 1996 Order). It states that a child is considered to have special educational needs if the child has learning difficulties which call for special educational provision. A child is considered to have learning difficulties if he or she has a significantly greater difficulty in learning than the majority of their peer group, at the same age, or has a disability which prevents or hinders him or her from making use of educational facilities of a kind generally provided for children of the same age, in mainstream grant-aided schools. ${ }^{11}$

As regards the details of the new SEND Act, the first section is general in nature, placing a duty on the Education Authority to seek and have regard to the views of the child in the decision-making process of their SEN provision. It asserts the importance of the child participating in the decision and being adequately informed and supported as

7 Education (Wales) Measure 2009.

8 Children (NI) Order 1995, article 2(2).

9 Department of Education NI, 'Every School a Good School: The Way Forward for Special Educational Needs and Inclusion' (August 2009).

10 Department of Education NI, 'Special Educational Needs and Disability Bill: Explanatory and Financial Memorandum’ (January 2016) 1-3.

11 Education (NI) Order 1996, article 3(2)(a)-(b). 
necessary to enable participation. ${ }^{12}$ The following section provides that the Education Authority must prepare and publish a plan setting out arrangements to be made in relation to special educational needs, including a description of new resources and advisory and support services that the Authority proposes to make available. Authorities must publish their plans and bring them to the attention of people likely to be affected by their content. ${ }^{13}$

Additionally, the Act amends existing provisions contained within the 1996 Order, ${ }^{14}$ with a key element being the expansion of appeal rights for children. Section 11 provides children over compulsory school age with the right to request a statutory assessment and the right to appeal to a tribunal against certain decisions of the Education Authority. It also introduces a new duty on the Department of Education to make regulations to provide for cases where a child over compulsory school age lacks, or may lack, capacity to exercise his or her rights. These include the department making provision to determine whether a child lacks capacity in relation to the exercise of his or her rights, and for the parent of the child to exercise those rights where it is determined that the child lacks the capacity to do so. ${ }^{15}$

The expansion of participative rights provided for in the Act seemingly incorporates elements of Article 12 of the UNCRC and Article 7 of the UNCRPD. The right of children to be actively involved in the process of special education decisions reflects obligations expressed in Article 12(1) of the UNCRC, which explicitly provides that state parties shall assure to the child who is capable of forming his or her own views the right to express those views freely in all matters affecting the child and that those views will be given due weight in accordance with the age and maturity of the child. Furthermore, Article 7 of the UNCRPD expands upon Article 12 in relation to children with disabilities, noting that states parties shall ensure that children with disabilities have the right to express their views freely on all matters affecting them, their views being given due weight in accordance with their age and maturity, on an equal basis with other children, and to be provided with disability- and age-appropriate assistance to realise that right. This obligation seems to be met in the creation of new advice and support mechanisms for children in Northern Ireland to enable them to challenge a decision on the statementing process or to take a case to tribunal under section 11 of the Act. The right of children to take an appeal to the SEN tribunal is deeply rooted in the obligations emanating from Article 12(2) of the UNCRC which states that the child shall be provided the opportunity to be heard in any judicial and administrative proceeding affecting them, either directly, or through a representative or an appropriate body, in a manner consistent with the procedural rules of national law.

While the above participative rights guaranteed by the SEND Act are reflective of international guidance on children's right to participate in SEN decision making, a number of issues arise regarding SEN tribunals as they currently function which may negatively impact any attempt to involve children in the process. The empirical data gathered for this research highlighted a number of procedural and attitudinal issues which need to be considered as the Act takes legislative effect, to ensure that there is guaranteed fairness and administrative justice for those seeking to utilise this mechanism of legal redress.

12 Department of Education NI (n 10) 4.

13 Ibid; Special Educational Needs and Disability Act (NI) 2016, s 2.

14 Education (NI) Order 1996.

15 Department of Education NI (n 10) 7. 


\section{Potential barriers to the child's right to participate at SEN tribunals}

\section{PROCEDURAL ISSUES: LEGAL CAPACITY AND SOCIO-ECONOMIC FACTORS}

Responses from interviewees highlighted significant, general barriers to participation faced by adults in their engagement with the SEN tribunal process. These structural and cultural barriers to adult participation raise a fundamental question: if indeed parents are struggling to access the system, how are we to expect children to fit seamlessly into the existing process?

Tribunal panel members pointed to the fact that the hearing has become more paperbased, focused on an ever increasing bundle of documents, thereby excluding those with lower literacy rates. As one panel member noted:

I can't see a child tackling a 300 page bundle in size 10 font. Realistically that's not ever going to happen. So perhaps if you want to encourage people to take part then you need to look at the fundamentals of the system as well.

Previous research has indicated that the socio-economic background of users impacts significantly on the issue of accessibility to legal process. In particular, that economic barriers and especially poverty lead people to have little or no access to either information or adequate representation. ${ }^{16}$ Furthermore it has been advanced that often SEN tribunals are considered a 'weapon of the middle classes', with few appeals being made from people living in socially disadvantaged areas and from ethnic minority families. ${ }^{17}$ Previous research in Northern Ireland found that the SEN tribunal was perceived by tribunal members to favour participation by educated parents, leading to the consequence that the process was viewed as being very 'middle class'. ${ }^{18}$

Findings from this research reiterate that sentiment, with tribunal panel members noting that the tribunal, as it currently exists, is too often a mechanism of the middle class, with too many people from poorer backgrounds lacking knowledge or understanding of the system, thereby being rendered unable to take part in the process. This flags a number of serious concerns regarding the SEN tribunal's capacity to be inclusive as, theoretically, it has been identified that truly participative forums are those which are accessible to all societal groups, including the usually excluded and hard-toreach, and are not dominated by interest groups. ${ }^{19}$

Education, as an empowerment right, can act as the primary vehicle by which economically and socially marginalised adults and children can lift themselves out of poverty and obtain the means to participate fully in their communities. ${ }^{20}$ In terms of SEN tribunals, these may be viewed as mechanisms to address recognition of an inequality in the provision of education and to subsequently redistribute resources to remove the

16 Mauro Cappelletti, 'Alternative Dispute Resolution Processes within the Framework of the World Wide Access-to-Justice Movement’ (1993) 56 Modern Law Review 282, 282.

17 Harris et al (n 5); Neville Harris, Education, Law and Diversity (Bloomsbury 2007) 352-3; Shelia Riddell, Sally Brown and Jill Duffield, 'Conflicts of Policies and Models: The Case of Specific Learning Difficulties' in Shelia Riddell and Sally Brown (eds), Special Educational Needs in the 1990s (Routledge 1994).

18 Grainne McKeever, 'Supporting Tribunal Users: Access to Pre-Hearing Information, Advice and Support' (Law Centre NI 2011).

19 Nancy Fraser, 'Social Justice in an Age of Identity Politics: Redistribution, Recognition and Participation' (1996 Tanner Lectures on Human Values: Stanford) 30; Cheryl Simrell King, Kathryn M Fetly and Bridget O’Neill Susel, 'The Question of Participation: Towards Authentic Public Participation in Public Administration' (1998) 58 Public Administration Review 317.

20 United Nations Committee on Economic Social and Cultural Rights, 'General Comment 13' (8 December 1999) UN Doc E/C12/1999/10, 1. 
inequity. Yet, if the tribunal process is inaccessible to certain members of society, the system exacerbates, rather than dissipates, injustice. If, as demonstrated above, those from an affluent social stratum are the group predominantly accessing the tribunal system, this in turn sees the movement of educational resources to those more affluent groups following successful appeals to tribunal, whilst those from lower socio-economic backgrounds become further entrenched in inequality, unable to access the system and similarly unable to acknowledge or verbalise the maldistribution. ${ }^{21}$

Essentially, administrative tribunals exist to ensure that public servants are applying the law consistently, fairly and equitably, and as intended by policy-makers. ${ }^{22}$ They bolster our ideas of democracy in that they permit individual citizens to question administrative decisions of the state. Yet, if the tribunal system is skewed, either through its facilitation, process or procedure, it functions as a defective cog within the democratic mechanism, leading to failings within the overall system.

\section{ALTERNATIVE DISPUTE RESOLUTION}

As with other jurisdictions the SEND Act places an increased emphasis on the utilisation of mediation prior to taking a case to tribunal. Section 10 of the Act sets out that a person intending to bring an appeal to tribunal must first seek and be provided with independent information and advice about pursuing mediation. Once they have sought advice, the mediation service provider will issue a mediation certificate, now a prerequisite to enable lodgement of an appeal to the SEN tribunal in Northern Ireland. ${ }^{23}$ This section does not apply to certain types of appeal, namely those which relate only to the school or other institution named in a statement maintained under article 16 of the Education (NI) Order 1996; the type of school or other institution named in a statement under that article; or when a statement does not name a school or other institution. ${ }^{24}$

Recent policy has seen a shift towards the use of alternative dispute resolution (ADR) within the field of administrative justice, including both mediation and conciliation approaches. $^{25}$ In Northern Ireland, the Dispute Avoidance Resolution Service (DARS) provides mediation in an informal forum and aims to explore differences and points of agreement and disagreement to find a way forward during educational disputes. ${ }^{26}$ Yet, research would indicate that knowledge of and access to mediation services may prove difficult for children, particularly without specific advice and support and, additionally, the fairness of the outcomes of such mediation has been questioned in relation to SEN disputes. Therefore, employing mediation for SEN disputes is increasingly considered contentious. ${ }^{27}$

Prior to accessing the tribunal system, ADR services had been utilised at the onset of educational and disability discrimination disputes by a number of respondent families in Northern Ireland. When questioned about their experiences of mediation, those

21 Neville Harris and Emily Smith, 'Resolving Disputes about Special Educational Needs and Provision in England' (2009) 10 Education Law Journal 113; Ellen Wiles, 'Aspirational Principles or Enforceable Right? The Future for Socio-Economic Rights in National Law' (2006) 22 American University International Law Review 35, 56-8; Michael R Anderson, 'Access to Justice and Legal Process: Making Legal Institutions Responsive to Poor People in LDCs' (Institute of Development Studies 2003).

22 Lens (n 2) 382.

23 Department of Education (n 10) 6-7.

24 Special Educational Needs and Disability Act (NI) 2016, s 10.

25 Anne Ruff, 'Quick, Private and Inexpensive' (2011) (spring) Judicial College Tribunals 14.

26 Department of Education NI, 'Supplement to the Code of Practice in the Identification and Assessment of Special Educational Needs' (September 2005) 27-30.

27 Harris et al (n 5) 29-31. 
interviewed were quite dubious in relation to the effectiveness of the service and raised concerns regarding the resoluteness of outcomes reached during the resolution process. ${ }^{28}$ As one parent noted: 'I didn't go down the DARS route because there was no point.'

Another stated:

I contacted the Children's Law Centre which is a charity and I contacted DARS as well. And well DARS, there was no point. . Because I mean, they were putting forward these different things to try and that was fine but whenever [the DARS Representative] went back to the Board, the Board just dismissed [the DARS Representative].

Another parent from Northern Ireland relayed concerns regarding the advice she had received during mediation, which was to make an appeal to the tribunal in an attempt to force the school to settle. This action had the opposite effect, with the school in question refusing any further communication with the parent and advising the parent to converse directly with the school's solicitors.

Scepticism in relation to ADR reflects other such research which highlighted parental concerns that ADR outcomes are not legally binding and that there is therefore a greater risk that rights will not be safeguarded through this mechanism. ${ }^{29}$ As other recent research suggests, in cases of SEN disputes there are doubts regarding the costeffectiveness of such approaches and about whether they extend the scope for settlement or the resolution of disputes. ${ }^{30}$ Harris highlights the statutory duty placed on education authorities through the statementing system and questions if arrangements settled via mediation can guarantee that duty; maintaining such mediation may be intrinsically unsuitable in SEN cases where there is little scope for compromise. ${ }^{31}$

Conceptually, there are also concerns regarding the balance of power between those participating in a citizen-versus-state forum without independent judicial processes. The fact that they are private hearings can be contentious, particularly in terms of transparency and fairness, and concerns have been raised regarding their appropriateness for cases regarding fundamental human rights. ${ }^{32}$ There is an elemental unease that ADR may affect the justice of outcomes in a negative way. On this point research suggests that people may settle for less than they are entitled to for convenience, thereby compromising their legal rights. ${ }^{33}$

The use of ADR as a method to resolve educational disputes should be adopted tentatively, particularly as children can now be brought into the mediation process and expected to negotiate on their own behalf in a process where there may be an imbalance of power. It may assist in opening the lines of communication between the parties in dispute, creating an understanding of both sides of the argument and, in conjunction with pre-hearing advice and support, helping to mitigate the need to progress to tribunal. Mediation can be highly effective if the problem relates to interpersonal communication, which may be resolved by reflection on the issues and agreement concerning the way forward. ${ }^{34}$ When the dispute concerns resource allocation, mediation can lead to less

28 Orla Drummond, 'When the Law is not Enough: Guaranteeing a Child's Right to Participate at SEN Tribunals' (2016) Education Law (forthcoming).

29 Sheila Riddell, Joan Stead, Elisabet Weedon and Kevin Wright, 'Dispute Resolution and Avoidance in Special and Additional Support Needs in England and Scotland' (University of Edinburgh 2010) 4.

30 Harris (n 2) 35-40.

31 Ibid.

32 Harris et al (n 5) 5.

33 Ibid 29-31.

34 Neville Harris and Emily Smith, 'Resolving Disputes about Special Educational Needs: Cross Border Comparisons and Reflections’ in Harris and Riddell (n 2) 198. 
assertive and knowledgeable participants achieving a worse settlement than they would have done through more open judicial processes. 35

\section{DIFFICULTIES IN ACCESSING SUPPORT: PERCEPTIONS, REALITY AND TRIBUNAL-BASED INFORMATION}

Pre-hearing advice and support are necessary prerequisites to enable meaningful participation in the tribunal process. It is essential that those who wish to utilise this mechanism of redress have knowledge of the legal system and legal rights. Research highlights that it is vital that citizens are equipped with knowledge to engage with both formal and informal legal networks, as a pervasive lack of such knowledge can lead to unnecessary levels of helplessness even among the most confident and resourceful. ${ }^{36}$

Findings from the research conducted for this article indicated that parents from Northern Ireland sought support from a number of local organisations including local politicians, Members of Parliament and local charity organisations, such as Autism NI. It is important to note that for the purposes of this study all Northern Irish parents were recruited through the Children's Law Centre and therefore had prior contact with this service, although support from the organisation varied from general advice to legal representation at SEN tribunal hearings. While many praised the Children's Law Centre for its guidance and legal assistance, parents noted difficulty in accessing support services in general. As one parent noted:

We kept hitting brick walls every time we asked for help. Nobody would help us. And it all came down to funding and that's what we were up against the entire time... There's very little support and it's a scary, scary thing because you're fighting for your child's right to be educated.

Additionally, parents complained that tribunal-based literature did not prepare them for the process, claiming inconsistencies between the informal hearing they expected and the formal, legal process they experienced on the day. Concerns were raised about the unrealistic amount of paperwork expected to be submitted, the engagement with legal jargon and the restrictions of time limits. ${ }^{37}$ These points reinforce the need for access to early and appropriate advice and assistance, so that those engaging with the tribunal have the skills and knowledge to do so, or to effectively mitigate the need to progress to the tribunal at all. 38

\section{LEGALISTIC, FORMAL AND INTIMIDATING TRIBUNAL ENVIRONMENT}

Tribunals are often regarded as accessible and informal alternatives to the traditional court-based resolution of legal disputes. These types of redress mechanisms were originally developed as a response to the perceived shortcomings of traditional courts, establishing simplified methods of resolving disputes to improve access to justice for all sections of society. ${ }^{39}$ Yet many respondents from this study found the process complicated, time-consuming, legalistic and 'borrendous' and struggled to access support to deal with problems they encountered. For many parents their anxiety was heightened due to the fact that they were fighting to obtain the desired outcome for their child. As one parent stated:

35 Ibid.

36 Hazel Genn, Paths to Justice: What People Do and Think about Going to Law (Hart 1999) 255.

37 Drummond (n 28).

38 McKeever (n 18) 40.

39 Tom Mullen, 'A Holistic Approach to Administrative Justice?' in Michael Adler, Administrative Justice in Context (Hart 2010) 390; Hazel Genn, 'Tribunals and Informal Justice' (1993) 56 Modern Law Review 399, 395-7. 
I found it intimidating enough myself and I'm reasonably eloquent and I was very sure that I was right . . . but it meant so much to me that I got what I needed for my child that I was very, very nervous on the day.

Parents expressed the view that the tribunal hearing was daunting and court-like, with many struggling with the complexity of the process. These findings reflect other such research which notes that tribunal hearings often involve highly complex rules and case law and can be, therefore, adversarial and legalistic, meaning that those without legal representation are often unable to sufficiently understand the proceedings so as to participate effectively. ${ }^{40}$ As Mullen asserts, during tribunal proceedings participants are required to speak to the legal narrative upon which the tribunals must adjudicate. Those lacking such skills are at a considerable disadvantage. ${ }^{41}$

In relation to child participation in the process, parents were adamant that children should be shielded from this adversarial environment. Based upon their experiences of tribunal hearings, parents noted that it was too volatile a process to involve children. As one parent relayed:

So I think it's important for kids to have their voice. I think that someone speaking for them though is better than the child actually having to be put under that pressure . . because it got heated a few times and I don't think that's appropriate for a child, especially with special needs.

A representative from an Education Authority noted that the tribunal hearing is often a lengthy, formal, stressful, legalised process which would be inappropriate for a child. This was reaffirmed by a SEN tribunal panel member who stated that the hearings are too judicial and that the child may become nervous and frightened. When asked if children should be permitted to attend SEN tribunal hearings as they currently exist, parents were resoundingly negative. As a parent firmly asserted:

Where the tribunal is at the moment, now? Definitely not! Because it's too volatile . . it's not run well enough and it's not organised enough. It's a free for all . . . it would be detrimental to the child.

Another noted: 'I still think that something like that would be very traumatic for a child.'

One child who had attended two SEN tribunal hearings was interviewed as part of the research. The child relayed concerns about the process stating:

It was very formal. It's definitely an adult environment not a child environment . . . I didn't expect how I was going to feel. . . completely uncomfortable. I felt like I was being judged the entire time... I literally wanted to just get up and run. I was tempted a few times and I started on a couple of occasions as well.

In addition to parental wishes to shield children from adversarial hearings, there were also protectionist views from all stakeholders that children should not be privy to sensitive personal information which could have a detrimental effect on their psychological well-being. ${ }^{42}$ For some parents in Northern Ireland this included safeguarding the child from knowledge of their own special educational need. As one parent asserted: ' $M y$ child has never been aware that there is anything wrong with him.'

40 Genn (n 39) 397-409; Jona Goldschmidt, 'The Pro Se Litigant's Struggle for Access to Justice' (2002) 40 Family Court Review 36; Deborah Rhode, 'Access to Justice: Connecting Principles to Practice' (2004) 17 Georgetown Journal of Legal Ethics 369.

41 Mullen (n 39).

42 Aoife Daly, 'The Right of Children to be heard in Civil Proceedings and the Emerging Law of the European Court of Human Rights' (2011) 15 International Journal of Human Rights 441, 441; Neville Harris, 'Education Law: Excluding the Child' (2000) 12 Education and the Law 31, 35. 
In this case the parent was adamant that they would not involve their child under any circumstances, stating:

Even if I'd taken it to the court, to the High Court, I would never have had [my child] in court or speaking about it because in [my child's] head and in [my child's] world, he's the smartest child and there's nothing... be's perfect. So I would never, ever have went down that route and it was nothing to do with ... well, part of it is protection for your child.

The concerns of key stakeholders in relation to the SEN tribunal as it currently exists require careful consideration by the Department of Education and the Department of Justice as the SEND Act takes effect. The Department of Education may find parents extremely reluctant to permit their child to enter a process which they feel will detrimentally impact their health and well-being, given that many have spoken of the effects that taking a case to a tribunal had on their family life, the damaging impact on their mental health, the strain on marital relations and the financial implications of taking a case. As one parent stated:

It puts a lot of pressure on your relationship, your marriage, your family. It puts a hell of a lot of pressure. I don't think I can emphasise how much pressure it puts on families going through all this. Because it is very traumatic and it did put a strain on my marriage because I was living, breathing and eating this.

Another parent simply noted: 'Family life was at breaking point.'

\section{INEQUALITY OF LEGAL ARMS}

One of the key issues identified by respondents as exacerbating the adversarial environment was the inequality of legal arms between the parents and the Education Authority. This raises explicit concerns regarding the fairness of the tribunal hearing in Northern Ireland, with parents feeling overpowered by the legal might of the opposing side. One stated:

Well I think it's just totally stacked against you. If they can bring a barrister and a solicitor and you're on your own. That's not an open and fair playing field.

Another said:

I didn't think the tribunal itself was an even playing field. I didn't think any of it was an even playing field at all.

Apprehensions regarding an inequality of arms and the unfairness of the tribunal environment were reiterated by a member of the SEN tribunal who noted:

The biggest change in terms of accessibility, by which I think you probably mean fairness to the tribunal users, would in my view be the availability of experienced representatives. Some parents are extremely able in presenting their case and presenting their child's condition. Others are not and struggle and you would also have very capable and intelligent people who simply don't know the system and how could they be expected to? In my experience the single biggest factor affecting fairness and accessibility is experienced representatives.

Power imbalances can have a negative impact on the ability to meaningfully participate and one of the fundamental conceptual prerequisites for truly participative processes is the guarantee of equality within the process of engagement. ${ }^{43}$ This applies just as much to opposing parties within a legal dispute and is of particular importance when addressing the power imbalance in citizen-versus-state proceedings.

43 Sherry Arnstein, 'A Ladder of Citizen Participation' (1969) 35(4) Journal of the American Institute of Planners 216, 216; Bill Cooke and Uma Kothari, 'The Case for Participation as Tyranny' in Bill Cooke and Uma Kothari, Participation: The New Tyranny? (Palgrave Second Impression 2002) 1; Peter Somerville, 'Democracy and Participation' (2011) 39(3) Policy and Politics 417, 418. 
Additionally, findings from this research reinforce other empirical studies that have found that the approach and attitude of the panel and legal representatives can have either a positive, enabling effect on participation or a detrimental impact on those taking part. ${ }^{44}$ In terms of notions of procedural fairness the quality of interpersonal treatment is essential to a procedure being viewed as fair. ${ }^{45}$ It has been found that people value the feeling of being treated with dignity and respect by authorities and that this contributes to their sense of justice. ${ }^{46}$ Yet respondent parents from this research claimed that, during the SEN tribunal hearing, they experienced questions concerning their personal abilities or parenting skills from both the panel and opposing side. Some reported feeling belittled, while others felt that their child was insignificant within the process. As a parent from Northern Ireland stated:

There's me sitting there and they have a solicitor and a barrister facing me. So like, you don't really stand a lot of a chance. And the [panel member] has been rude to me and criticised the manner of my asking questions or talking, which he hasn't done to anybody else.

Many parents felt that their role within the process was both secondary and inferior. There was a distinct sense of powerlessness, which contributed to the difficulty of voicing their case. At present parents feel that they are an unequal partner in an already unbalanced domain. Findings from this research indicate that feelings of inequality expressed by parents have been powerfully influential on their perceptions of procedural fairness whether the outcome was successful or not.

In terms of child participation, the inequality of legal arms within the process has triggered further notions of protectionism among parents and panel members. Parents relayed fears regarding the role of legal representation in the process and, while they generally agree that children should have a say in the dispute, parents are hesitant in relation to their own child encountering a tense and adversarial legal hearing and being crossexamined by legal representatives. ${ }^{47}$ One SEND tribunal panel member pinpointed the general concerns of balancing child participation within an inherently legal process, noting:

What I want is what's best for the child and being best for the child is not being aggressively questioned by an over ambitious young barrister.

If children are to enter the tribunal environment, as envisaged by the SEND Act, it is essential that concerns about the inequality of legal arms are and addressed. As Lundy makes clear, children require a safe and inclusive space to engage and express their views. ${ }^{48}$ The findings from this research evidence that at present SEN tribunals do not create the optimum environment for meaningful participation of children. In order to deal with parental concerns and encourage the participation of children in tribunals, the setting, the legal representation, the adversarial approach and the formality of the process all need to be looked at.

\section{ATTITUDINAL BARRIERS - MEASURING CAPACITY}

As noted earlier, section 11 of the SEND Act amends the 1996 Order for the purpose of conferring on a child over compulsory school age who has, or may have, special educational needs certain rights previously exercisable only by the parent of that child. In

44 Michael Adler, 'Tribunals Ain't What They Used to Be' (2009) (March) Adjust Newsletter.

45 Tom R Tyler, 'Procedural Justice, Legitimacy, and the Effective Rule of Law' (2003) 30 Crime and Justice 283, 298-301.

46 Ibid 298-301.

47 Drummond (n 28).

48 Laura Lundy, "Voice" is Not Enough: Conceptualising Article 12 of the United Nations Convention on the Rights of the Child' (2007) 33(6) British Educational Research Journal 927, 931-3. 
particular, the child now has the right to challenge decisions on the statementing process and if necessary can appeal to the SEN tribunal. One outstanding caveat is that Department of Education Regulations will determine and make provision for cases where a child over compulsory school age lacks (or may lack) capacity to exercise any such right. ${ }^{49}$ If the child is deemed to lack the capacity to take a case to the tribunal then those rights are transferred to the parent. The draft regulations issued for consultation by the department note that if a question is raised concerning the child's capacity, by the child themselves, their parent(s), the Education Authority, an educational or health or social care professional who knows the child, or by the tribunal, the Education Authority must determine the child's capacity. In addition, the Education Authority will discuss the matter with the child in question and, where reasonably practicable, with the parent(s) and others as it deems fit. 50 Capacity, as set out in the draft regulations, is to be measured by the child's ability to understand the information, their understanding of the rights bestowed on them and what is being asked of them, and the child's ability to act in an informed way in order to exercise those rights. ${ }^{51}$

Essentially, the rights of the child to appeal to a tribunal ultimately rest upon this definition of capacity and the department's substantive interpretation of it - a benchmark which is often not as simple to formulate or as easy to apply as might be thought. The Education Authority has the final say in determining the capacity of the child, a position which is less than ideal for the enhancement of meaningful participation. Since the creation of international children's participative rights the notion of capacity has been invoked as a main reason for denying children their rights to influence decisions that affect them. Children's rights are often qualified by our understanding and theorisation of childhood accentuated by notions of emotional and cognitive incompetence, and based on the principle of 'best interest'. ${ }^{52}$

In relation to opinions on age and capacity, respondents for this study claimed that children may not be aware of what is best for their education. As one member of the Education Authority in Northern Ireland noted:

\section{A lot of the time it's about wording on a statement that maybe parents are concerned about or certain provisions and the child might not be developmentally at an age appropriate or cognitively tuned into what their best needs are.}

These findings echo Harris's assertion that the underlying basis for the suppression of children's rights to parental authority is that it is generally accepted that the child may lack the competence to make decisions and, therefore, must be protected from damaging their long-term interests through inappropriate choices. ${ }^{53}$ This central issue incorporates components of debates concerning the age, capacity, disablement and protection of children participating at SEN tribunals, creating a conceptual stumbling block to the realisation of meaningful participation. ${ }^{54}$

The transference of the right to appeal from the parent to the child enacted in the SEND Act may be considered, by many key stakeholders, as controversial and could possibly be met with substantial parental resistance. In terms of power relations in the

49 Special Educational Needs and Disability Act (NI) 2016, s 11(3).

50 Department of Education NI, Draft Special Educational Needs (SEN) Regulations (22 February 2016) 27-8.

51 Ibid.

52 Elizabeth Such and Robert Walker, Young Citizens or Policy Objects? Children in the "Rights and Responsibilities” Debate' (2005) 34 Journal of Social Policy 39, 41-3.

53 Neville Harris, 'Grievances, Disputes and Education Rights' in Harris and Riddell (n 2) 12-13.

54 Drummond (n 28). 
private sphere, the formidable value of the parental role was discernible in the findings of this research. The role of the parent as the key decision-maker manifested as an undercurrent throughout interview responses, as did the fact that parents felt it was their role to champion their child's opinion. As one parent noted: 'As his parents it is up to us to understand what [our child's] needs are and find the best fit of school.'

Another stated:

We made [our child] aware of nothing and I think where that's concerned it all depends on the child. And I think you decide what's best for your child.

These findings link specifically to theoretical considerations of the asymmetrical power relations between children and adults and in particular to Hinton's explanation that traditional theorisations of childhood have conceptualised children as passive recipients of care to be placed in the private sphere. ${ }^{55}$ Once placed within the private realm their interests are considered best served through the decisions and voice of their parents and this, in turn, impacts upon the enablement of 'child' citizenship and participation. ${ }^{56}$ Indeed, one of the main concerns among interviewees regarding granting children wider participation within the process is the contention that differing opinions between the child and their parent would be difficult to reconcile: in essence, whose voice would take precedence? This conceptual hurdle, particularly the notion that the enhancement of child participation would lead to the corrosion of adult authority, has been a major reason to deny children access to their participatory rights. ${ }^{57}$

In terms of the new SEND Act, the Department of Education may find parents utilising the capacity 'opt-out' as a way of protecting their child from becoming embroiled in the educational dispute. As noted in earlier research, for children with special educational needs, the capacity debate is further complicated by the disparity created by society's perception of disability and disablement. In its findings, parents continually referred to the nature of their child's disability as a reason for exclusion from the legal process. An example of a typical response was:

Well because my daughter is so far behind compared to her peers . . . basically it wouldn't have been appropriate, I think, even to question her because basically she can't cope with change.

When specifically asked why their children had not participated in their SEND tribunal hearing, one of the main reasons provided by respondents, particularly those from Northern Ireland, for not involving the child was their age. As a parent stated: 'No, [our child] is 10. No, be's definitely too young.'

Another added:

No, he's too young. He's only 6. So I kind of felt he was maybe a bit too young. If he had of been older then yes... So I just thought no, I'll not because to be honest I didn't really want to upset him either with all the decisions.

In general, most respondents' views on age were inextricably linked to notions of the child's capacity to be involved. Many expressed the view that younger children should not participate in tribunal hearings because they lacked skills, maturity and aptitude by virtue of their age. As noted by one Northern Irish panel member:

55 Rachel Hinton, 'Children's Participation and Good Governance: Limitations of the Theoretical Literature' (2008) 16 International Journal of Children's Rights 285, 293.

56 Tom Cockburn, 'Children as Participative Citizens: A Radical Pluralist Case for "Child-Friendly" Public Communication' (2005) 9 Journal of Social Sciences 19, $23-4$.

57 Such and Walker (n 52) 43. 
In principle I think a more active role is fine but it very much depends on the facts of the case, disabilities the child has, what needs to be discussed and the age of the child. So in principle yes, but subject to the individual facts to each case. . . it could be entirely inappropriate in certain cases.

In essence the Department of Education's move to benchmark the child's ability to participate solely against their perceived capacity may actually diminish any attempts to meaningfully engage with the child. As an Education Authority representative observed:

\section{If they're at a certain age and development level where they are able to participate then they should. I think their views should be sought but my experience and I suppose the [Education Authority] experience is that the vast majority of children aren't at the developmental stage to be participating.}

The Department of Education would be wise to follow the guidance from the UN Committee on the Rights of the Child, which specifically states that the every child's right to be heard if he or she is 'capable of forming his or her own views' should not be seen as a limitation, but rather as an obligation for state parties to assess the capability of the child to form an autonomous opinion to the greatest extent possible. Parties cannot begin with the assumption that the child is incapable of expressing his or her own views, but should instead presume that the child has the capacity and has the right to express them. ${ }^{58}$ It should also be noted that Article 7 of the UNCRPD, assuring children with disabilities the right to express their views freely on all matters affecting them, is not restricted by capability and it places an obligation on the state to provide children with disability- and age-appropriate assistance in order to realise the right. Additionally, Article 12 of the UNCRPD provides that state parties must recognise that persons with disabilities enjoy legal capacity on an equal basis with others in all aspects of life. It also obliges states to take appropriate measures to provide access by persons with disabilities to the support they may require in exercising their legal capacity.

\section{THE CAPACITY OF JUDICIAL STAFF TO ENGAGE WITH CHILDREN}

Since the discussion surrounding children's participation is often centred on the capability of the child, panel members and tribunal staff were asked if they felt they had the personal capacity to engage with children within the tribunal setting. As Walker states, competency as a witness in court involves measuring the capacity to understand the questions and the ability to make intelligent answers, yet there is no reciprocal test that questioners must meet which measures their aptitude to ask intelligent, easily understood questions. ${ }^{59}$ This concern was raised in research by Donnelly, referring to the case of $\mathrm{R} e$ $H$ and $C^{60}$ when Mr Justice McLaughlin stated that he did not have the professional skills for interviewing young children. ${ }^{61}$ In relation to the findings of this research, in Northern Ireland two panel members stated that they felt they had the capacity to engage with children within the tribunal setting, while one did not and questions were raised regarding other panel members' ability to converse with children.

58 UN Committee on the Rights of the Child, General Comment 12 (20 July 2009) CRC/C/GC/12.

59 Anne Graffam Walker, 'Questioning Young Children in Court: A Linguistic Case Study' (1993) 17 Law and Human Behaviour 59, 59.

60 Re H and C [2005] NIFam 1; also see Lesley Emerson et al, 'The Legal Needs of Children and Young People in Northern Ireland: The Views of Young People and Adult Stakeholders' (Centre for Children's Rights, Queen's University Belfast 2014).

61 Cathy Donnelly, 'Reflections of a Guardian Ad Litem on the Participation of Looked-After Children in Public Law Proceedings' (2010) 16 Child Care in Practice 181, 186. 
When asked if they had the capacity to interact with children within the legal setting one panel member replied with complete honesty, stating:

Well it's an interesting question. I really don't know and I suspect not . . I mean as an individual and a personality I have no difficulty getting on with children but in terms of a judicial setting I would welcome additional training because really I don't know.

Another noted how the language of the tribunal may need to be adjusted for child participants, noting:

I mean I have no difficulty in that area but if I'm honest I know of other members of the tribunal who would have no experience in dealing with children... and there'd probably bave to be training because how you ask a question of a child is very different to how you ask it of an adult.

The exploration of judicial capacity to engage with children is extremely important when considering participation at tribunals and is an area which requires further research. As Walker notes, poorly worded questions may simply be a nuisance when addressed to an adult, but for a child they may be a serious source of miscommunication. ${ }^{62}$

All of the panel members interviewed noted the need for additional training on communicating with children within the legal setting and welcomed specialist advice on the matter. When asked if they felt in need of additional training and support one stated: 'I believe that, absolutely yes.'

Another added:

Ob absolutely, but it wouldn't be just the panel staff. I mean, for example, barristers and lawyers brought in would need specialist training. Some of the barristers can be actually quite aggressive.

This need for specialist legal education reiterates findings from recent research which highlighted the inappropriate treatment of children and young people by judges in legal settings in Northern Ireland and emphasised the need for child-focused selection procedures, monitoring and appraisal of judiciary working with children. ${ }^{63}$

\section{JUDICIAL ATTITUDES TO CHILD PARTICIPATION AT SEN TRIBUNALS}

A further barrier to the introduction of child rights initiatives in legal process could be the attitude of judicial staff on the implementation of such approaches. The findings from this research highlighted a significant geographical disparity in the opinions of judicial staff to the introduction of a child's right to appeal. Panel members' responses in Northern Ireland, when asked if children should have a more active role in the process, were tentative and reflected traditional views on exposure to sensitive personal information and parental protectionism. As one panel member stated when asked if children should be party to SEN tribunal hearings:

I couldn't give you a yes or no because I think there have been occasions when I thought I wish I had the child here to ask the child the truth about ... where for example the parent says something isn't happening in the school and the school says it is happening. On the other hand I don't know if I would want, just say this was my own child, I don't want my own child taking part in proceedings where their mental ability might be discussed. Would you want a boy of 14 to be told that his IQ was 65? It's a difficult area.

When asked about the possible implementation of a child's right to appeal in Northern Ireland, another panel member observed:

62 Walker (n 59) 59.

63 Emerson et al (n 60) 63. 
Well it's an absurd notion. A five year old wouldn't know what an appeal was . . I think that's something that could be used because a child could be manipulated into appealing. I'm not really sure about that because there's no age limit laid down I'm thinking if you're over fourteen certainly. When you're cognisant of it all you should have the right to appeal. If you're five well it's not you appealing at all it's your mummy or your granny. I'm not sure that I would agree with that in that present form.

Additionally, when asked if the enhancement of child participation at a SEN tribunal would require a proactive campaign with children and families, a panel member replied no, that it would require a more pro-active campaign with the judiciary. Fundamentally, SEN tribunal members' responses to questioning on the expansion of children's participatory rights were based on traditional conservative theorisations of childhood. ${ }^{64}$ This conservative approach reflected general conceptualisations of childhood, placing parental deference at the nucleus of the process. Traditional notions of age, capacity and protectionism were upheld as reasons for excluding children from the process, instead of being recognised as barriers to be dismantled.

\section{Conclusion}

While the SEND Act 2016 is a welcome attempt to incorporate the obligations emanating from Article 12(2) by providing a new child right to appeal to the SEN tribunal, there remain a number of persistent barriers for current users that may negatively impact on the new initiative. As evidenced above, there are concerns that the process presently excludes those from lower socio-economic backgrounds, those with lower literacy rates and those with low confidence and legal capacity. This research suggests that participants should not be excluded from the process because of low skills, lack of confidence about appearing before a panel, or their disability or age. ${ }^{65}$ As Mullen and Genn assert, citizens can vary in personal characteristics such as intellectual capacity, educational attainment, oral and/or written communication skills and psychological and emotional attributes such as confidence and emotional fortitude. ${ }^{66} \mathrm{It}$ is therefore essential to adapt processes and procedures to meet those needs and enable participation.

All participants require flexibility within the process to enable participation tailored to their individual needs. This would require, for example, developing the communicative capability of panel members and tribunal staff; utilising appropriate local settings for hearings; providing greater discretion to expand time limits; reviewing the requirement of paperwork; the development of informal, child-friendly procedures and literature; the use of informal, child friendly settings; and developing accessible tribunal-based information. ${ }^{67}$ Fundamentally, involving citizens in participatory processes requires careful planning, thoughtful preparation and flexibility to change procedures to meet the requirements of the affected constituencies. ${ }^{68}$

Findings from this research have also uncovered substantial difficulties for parents seeking advice and support following the onset of educational disputes. In order to enable meaningful participation at SEN tribunals participants require knowledge and advice about rights, obligations, remedies and procedures to ensure they have an adequate

64 Eithne McLaughlin, 'Governance and Social Policy in Northern Ireland (1999-2002)' in Martin Powell, Linda Bauld and Karen Clarke (eds), The Devolution Years and Postscript, Social Policy Review 17 (Policy Press 2005) 116.

65 Drummond (n 28).

66 Mullen (n 39) ii.

67 Drummond (n 28).

68 Ortwin Renn et al, 'Public Participation in Decision Making: A Three Step Procedure' (1993) 26 Policy Sciences 189, 209. 
understanding of the issues at stake and the possible outcomes of differing decisions. ${ }^{69}$ Additionally, ADR services were viewed sceptically by respondents, with concerns raised regarding the clarity of outcomes and the fear that rights would not be safeguarded through this mechanism. This is an issue which will become even more controversial when children are expected to negotiate a resolution within a mediation setting.

SEN tribunals have been described as formal, legalistic, and excessively adversarial, sparking protectionist views that children should be shielded from this process instead of being actively included. The eradication of the inequality of legal arms is urgently required to rebalance the inherent fairness of the tribunal and ensure administrative justice. ${ }^{70}$ One of the protectionist reasons for refusing children access to their right was the fear that they would encounter cross-examination by an over-zealous barrister and this is something which needs to be addressed to relieve parental concerns thereby enhancing their receptivity to involving their children in the process.

There is a need to ensure that participants do not feel belittled within the dispute resolution process and are shielded from unnecessary censure. It is essential, if children are to attend tribunals, that they can express their opinion in a safe environment without fear of rebuke or reprisal. ${ }^{71}$ Attitudinal barriers to involving children in the process remain culturally entrenched, with age and capacity continually cited as reasons for reducing children's right to participate, an approach which the SEND Act entrenches further. What is required is a conceptual shift, moving away from the need to shape the child to fit within the tribunal process, expecting them to reach the potentially unobtainable 'capacity' benchmark required for legal participation. Instead, participation should be a fluid concept, armed with evolutionary properties so, when faced with the challenges of specific needs, it can procedurally transform so as to hear children's voices as they express them, instead of expecting children to conform to some rigid standard of competence. Crucially, the findings from this research highlight that, in order to meaningfully hear the voice of the child within the process, particularly a child considered to have a disability, there is a requirement to be adaptive to their needs.

Granting children the full right to appeal should be considered only one step in a multifaceted approach to enable meaningful participation. Children have differences. Some have substantial, complex needs which may mean it is unrealistic to assume that they can physically attend the tribunal or present their own case. Yet this is not to suggest that those with complex needs cannot influence the decision-making process or have their voice heard within the proceeding.

The Welsh experience is one from which lessons can be learnt. Following the enactment of a child's right to appeal to a SEN tribunal, an evaluation of the legislative pilot found that systems and processes of informing children and young people of their rights were well established and generally regarded as working well. In reality, only one child had made a claim of disability discrimination during the pilot and no children had made appeals to SENTW. ${ }^{72}$ In addition, no children or young people availed of the advocacy or dispute resolution services established as part of the pilots. ${ }^{73}$ This research would suggest that the underlying procedural and attitudinal issues discussed above in

69 Thomas Webler and Seth Tuler, 'Fairness and Competence in Citizen Participation: Theoretical Reflections from a Case Study' (2000) 32 Administration and Society 566-95, 568; Genn (n 36) 255.

70 Drummond (n 28) above.

71 Lundy (n 48) 931-3.

72 Welsh Government, Evaluation of a Pilot of Young People's Right to Appeal and Claim to the Special Educational Needs Tribunal Wales: Final Report (2014).

73 Ibid. 
essence created an overwhelming barrier to child participation at SEND tribunals. Barriers were so culturally entrenched that they overwhelmed innovative legislative attempts to ensure children their right to participate. In relation to the notion of the child's capacity to participate, the Welsh government assessment acknowledged that a limited number of right-bearers would be able to understand and exercise their rights, an issue which this research has demonstrated is a pervasive barrier to participation not only for children but also adult users of tribunals. ${ }^{74}$

There is, therefore, a need to move away from conceptualising the meaningful participation of children at SEN tribunals as the total immersion of the child in the dispute resolution process. Fundamentally, what is being advocated as a result of this research is the development of processes, techniques and procedures to guarantee that children's voices are heard within the decision-making process, thereby ensuring that they can give their opinion on the nucleus of the disagreement and that their opinion is given weight within the process. If a child has complex needs, it is about tailoring the methods of extracting the child's opinion to suit the individual needs of that child, utilising approaches that reflect their method of communication.

The need for training to build the capacity and communication skills required to engage with children was highlighted by all but one of the tribunal members in Northern Ireland. This is obviously an area which requires immediate attention as the SEND Act takes effect, particularly if we are to effectively expand the inquisitorial role of the panel in an attempt to challenge the adversarial environment experienced by current users. It is about changing our perceptions of communication within formal settings and developing the skills of those involved in the tribunal process to enable that. This would include training, not only for tribunal staff and judiciary, but for the legal community in general. ${ }^{75}$

There is an urgent need to address the attitudinal concerns of parents involved in the processes and a need to educate them concerning children's rights. Findings from this research found that the traditional conceptualisation of children as being in need of protection from the process, knowledge of their disability and/or knowledge of the dispute, in order to protect their best interests, needs to be challenged. Reassuring parents that their children will not be exposed to an excessively adversarial environment or unnecessarily exposed to sensitive information may go some way to alleviate their concerns and may convince them to permit and encourage their children to participate.

The SEND Act has taken effect in Northern Ireland, expanding children's participatory rights into an environment rife with pre-existing procedural and attitudinal barriers. Historically, parents have struggled to take a case, find support, engage at the tribunal hearing and deal with the reality of their everyday lives. If this remains unchanged it is impossible to see how children with special educational needs can enter this domain and meaningfully participate. The Act is progressive, but perhaps what is required is a review of the existing SEN tribunal process, with a view to making the tribunal accessible for all. 